\title{
The effect of economic policies on North Macedonia's food system
}

\author{
Nikolche Jankulovski ${ }^{1 *}$, Katerina Bojkovska ${ }^{1}$, Goran Mihajlovski ${ }^{1}$ and Monika Angeloska Dichovska ${ }^{2}$ \\ ${ }^{1}$ Department of Agricultural Economics, Faculty of Biotechnical Sciences, St. Kliment Ohridski University, Bitola, \\ Republic of North Macedonia \\ ${ }^{2}$ Faculty of Economics, Branch Prilep, St. Kliment Ohridski University, Bitola, Republic of North Macedonia
}

\begin{abstract}
The agriculture system is a significant contributor to North Macedonia's Gross Domestic Product (GDP), but with substantial influence by economic policies. In 2020 , the sector contributed $9.09 \%$ against $7.87 \%$ in 2017 and the years before, contributing to past political insecurities. Agriculture performance needs to be reinforced with suitable economic policies, which would solve the prevailing complications in food systems. The temperate of North Macedonia is not favourable for food production, and irrigation is an effective means of providing water. The total arable land in North Macedonia is about 665,000 hectares, which is $50 \%$ of the total available land. Only about 163,700 hectares are provided with water through several government irrigation schemes. Aside from the country being water deficient, the mean temperature of the region is also high and is continually on the increase. It is estimated that in 2050 , the mean annual temperature would have increased $1.90^{\circ} \mathrm{C}$ and a decline of $5 \%$ in precipitation. North Macedonia can achieve more by having an increased growing season and changing cropping patterns to adapt to climate changes. Since the agricultural sector is less profitable, the government needs to enact more policies to improve the food system performance to experience positive returns.
\end{abstract}

\section{Introduction}

The agricultural system in North Macedonia is greatly impacted by climate changes. The region has several climatic conditions, which is used to categorize the different zones and influences the kind of crops grown in the country. There exist three agro-ecological zones (AEZ), the Alpine, Mediterranean and Continental. Continental zones represent about $61 \%$ of the total area in North Macedonia, while Mediterranean and Alpine cover $35 \%$ and $4 \%$, respectively. These three zones have varying temperatures that is typical of their climate, a variation from hot summer periods with a temperature between 20.6 to $24.3^{\circ} \mathrm{C}$ to cold winters with temperatures between 0.9 to $4.9^{\circ} \mathrm{C}$.

Besides the temperature variations, rainfall distribution varies across the agro-ecological zones, which also impacts the crop production. Research studies have it that the Western North Macedonia have favourable annual rainfall between $400 \mathrm{~mm}$ to about $1000 \mathrm{~mm}$, but the temperature is projected to increase by approximately $1.9^{\circ} \mathrm{C}$ and rainfall reduced by $3-5 \%$. These speculated climate changes would lead to drier environmental conditions resulting in reduced crop production.

\section{Research objectives}

* Corresponding author: nikolce.jankulovski@uklo.edu.mk
This research study is aimed at investigating the development and the effect of agricultural policies in Western Balkan countries, specifically Western North Macedonia. The study seeks to identify the primary agricultural data indicators that have significant influence on policy development and decision making. All designed to support decision-making activities with evidences about the agricultural policy.

\section{Literature review}

\subsection{Challenges to North Macedonian's food systems}

Food systems have evolved recently bringing in new challenges that threaten the existence of the same food systems. For instance, food systems have contributed to changes in climate, environmental destruction, air pollution and pollution in water and soils. It has also led to the overexploitation of natural resources, resulting in the significant challenges North Macedonia's food system is experiencing; reduced rainfall and increased

temperature [1]. Cottrell et al. [2] stressed the vulnerability of food systems in most countries to extreme weather conditions and man-made geopolitical crises. 


\subsection{Rainfall and temperature}

North Macedonia experience a yearly diverse climate due to the country's proximity to Mediterranean and continental air masses given rise to an agricultural sector that is diverse allowing specific crops to proliferate. The alpine and the Mediterranean divisions of the country are characterised by alternating periods of long drought and long precipitations, resulting in soil erosion and degradation when there are no proper policies to ensure appropriate soil management. A typical year in North Macedonia, evapotranspiration is higher than rainfall, reducing the amount of water available to food crops.

Between 2008 and 2012, the country experienced a significant loss in crop production, and it is speculated to increase as the temperature increase in the region [3].

Tiseo [4] analysed the countries that are most vulnerable to water stress due reduced water supply, rating them between $0-5$. Countries with a rating close to 5 or exactly at 5 had the highest water stress and North Macedonia have a water stress of 4.76 [4]. In 2016, North Macedonia applied a very high density of its land to grow tobacco. The country utilized about 16,376 (Fig. 1) hectares of land from its 2.57 million hectares to grow the plant; this is because the plant can adapt to low water availability or high-water stress [5]. Thus, more land portion were invested into tobacco farming. The implication of this action is that other food crops would be less grown, which would impact on its price, food availability and the eventual GDP contribution of agriculture in North Macedonia.

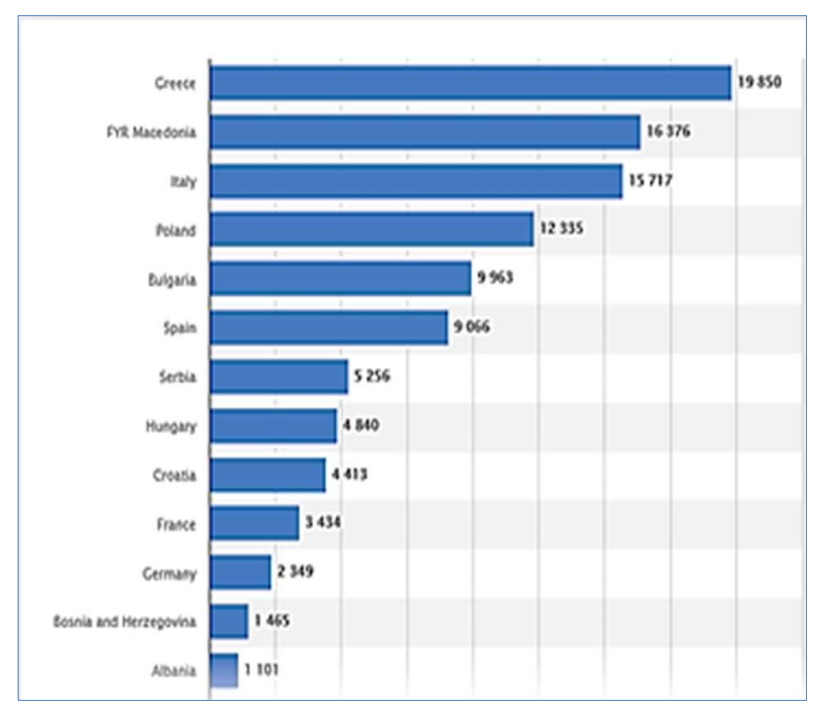

Fig. 1. North Macedonia land area planted with tobacco in 2016. Source: Statista Research Department, 2020 [5].

Aside from tobacco, other crop types easily grown are the forage crops, horticultural crops, fruit crops and viticulture. Cereals like barley, oats and maize were mostly cultivated, but as the temperature became unfavourable, farmers reduced their planting of cereal crops resulting in fluctuating yearly production. In 1995, there was 724,919 tons of cereal production, it reduced to 555,591 in 2002 [6]. It increased in 2004 to 681,933 tons and fell to 598,382 in 2018 [6]. Also, the growth of vegetables in the region (tomatoes, peppers, cabbage, cucumbers, melons and watermelons) in 2007 had good yields from the south east region of North Macedonia, which is a subtropical region characterized by relatively high temperatures and with good rainfall measures. However, with the changes in climate, the temperatures have increased with reduced rainfall, and the grapevines, tomato, wheat are the most affected vegetable crops in the South Eastern part of North Macedonia. Mihajlo et al. [7] speculated that by 2025 there would be about $72 \%$ decrease in tomato production in North Macedonia and by 2100 it would have gone to $82 \%$. For seeing the loss that could result in vegetable farming, the government invested in greenhouses for planting any of the desired vegetables.

\section{Methodology}

This current study shall draw information and data from governmental agencies, scholarly resources, and research agencies like Statista Research Department [5].

\section{Results}

Policies are any country state and guide the activities of the public, same goes with agriculture production in North Macedonia. The growth of vegetables has increased in greenhouses than in the open farmland, which is the effect of national policies and government interventions. The economy of North Macedonia is dependent on external trades of agricultural products, the service industry and production companies, consequently, the government is making concerted effort to align with the World Trade Organization (WTO). The government is also working towards ensuring its national agricultural policies align with the Common Agricultural Policy of the European Union.

The National Strategy for Agriculture and Rural Development (NARDS) 2007-2013 has its objectives to provide a consistent production of affordable and highquality food crops, providing a steady farmer's income, sustainable rural development and the optimal use of natural resources. This policy supported the growth of greenhouses in North Macedonia mostly for vegetable farming, and it has helped to increase consistently the production of vegetables despite the challenges with rainfall and temperature.

Even before the development of economic and agricultural policies, food systems in North Macedonia had been influenced by political powers from historical data. During the Ottoman feudal system, lands in North Macedonia were not owned by the locals. Rather the government owned the land, leased it out to the locals who in return pay taxes to the government. As trade between North Macedonia and the Western countries increased, development gradually came into the region and farmers began acquiring large hectares of land and revolting against the Ottoman feudal system. Eventually, North Macedonia gained freedom, and after the Second World War, North Macedonia started making regulations of the 
Agricultural Reform and Colonization Act, which impacted and improved food systems in the region.

Ever since the independence of North Macedonia, economic policies have been put in place, which had an impact on food systems, both negatively and positively. During the period of collectivization, several policies like the, the investment policy, credit policy, restricted land trade and the system of bound prices were enacted directed at incorporating farmers into a co-operative. The co-operatives increased in number as they encouraged farmers to cultivate arable lands and in exchange they provided the farmers with food and financial assets. Furthermore, into the coming years of 1957, the investment policy, and tax policy were modified and a new price policy was put in place. All these policies improved food systems in North Macedonia. Farmers had access to agricultural loans with little interest rates, they were also giving non-repayable funds, which improved food systems productivity and production.

Currently, the performance of the agricultural system is below its productivity compared with the previous years. Between 2000 and 2008, the share of agriculture in total employment reduced from $27 \%$ to $19.6 \%$, exportation of food crops from North Macedonia reduced from $12 \%$ to $11 \%$, while the importation of food crops into the country increased from $10 \%$ to $14 \%$. Economic policies over this period failed to promote and improve the productivity of agricultural systems. For instance, majority of persons are currently migrating from the rural areas in North Macedonia to the urban regions, in search of employments in other sectors. Policies have not favoured food systems in North Macedonia as much as other sectors like the industrial and service sectors are benefiting from economic policies. Part of the reason is due to the fact that North Macedonia has not been able to monitor and determine the effectiveness of policies that were enacted in the past. So, the lack of an evaluation period and assessment mechanisms resulted in the lack of direction in the agricultural system. Recently, the country increased effort to align with the European Union policy for future integration and alignment with the EU food quality and safety. To achieve this feat, positive changes have to be recorded in the effect of agricultural policies on farming.

\section{Conclusions}

The agriculture system is a significant contributor to North Macedonia's Gross Domestic Product (GDP), but with substantial influence by economic policies. In 2020 , the sector contributed $9.09 \%$ against $7.87 \%$ in 2017 and the years before, contributing to past political insecurities. The agricultural land covers about $40 \%$ of the region's territory and provides employment to about $20 \%$ of the population. Reduced activity is observed with agricultural practices and a large part of North Macedonia's agricultural land remains unused. Agriculture performance needs to be reinforced with suitable economic policies, which would solve the prevailing complications in food systems. Food systems have evolved recently bringing in new challenges that threaten the existence of the same food systems. It has also led to the overexploitation of natural resources, resulting in the significant challenges North Macedonia's food system is experiencing; reduced rainfall and increased temperature has also led to the overexploitation of natural resources, resulting in the significant challenges North Macedonia's food system is experiencing; reduced rainfall and increased temperature. This changes in climate have resulted in poor crop production and developing appropriate economic policies would rescue the sector from the impending doom.

\section{References}

1. S. Dury, P. Bendjebbar, É. Hainzelin, T. Giordano, N. Bricas, Food systems at risk: new trends and challenges (Food and Agriculture Organization of the United Nations, Rome-Montpellier-Brussels, 2019)

2. R. Cottrell, K. Nash, B. Halpern, T. Remenyi, S. Corney, A. Fleming, Elizabeth A. Fulton, Sara Hornborg, A. Johne, R.A. Watson, JL. Blanchard, Nat. Sustain. 2, 130-137 (2019)

3. USAID. Climate risk profile: North Macedonia (The Climate Integration Support Facility Blanket Purchase Agreement, Washington, 2018).

4. I. Tiseo, Water stress levels globally by country 2020 (Statista Inc., New York, NY, 2021).

5. Statista Research Department, Area of tobacco planted in European countries 2016 (Statista Inc., New York, NY, 2020).

6. World Bank. Cereal production (metric tons) - North Macedonia (The World Bank Group, Washington, DC, 2018).

7. L. Mihajlov, F. Trajkova, V. Zlatkovski, (2010) Proc. Second Balkan Conf. Biol. 1, 42 (2010) 